Thorax (1970), 25, 451.

\title{
Respiratory impairment and airway closure in patients with untreated idiopathic scoliosis
}

\author{
J. B J U RE, G. G R I M B Y, J . KA S A L I C K $\dot{Y}, M$. L I N D H, \\ and A. NACHEMSON \\ Departments of Clinical Physiology and Orthopaedic Surgery, University of Göteborg, Sweden
}

\begin{abstract}
Fifty patients aged 11 to 78 years with untreated idiopathic scoliosis were studied. An increased frequency of respiratory impairment was found, especially in patients with a severe degree of scoliosis. Seven patients under 60 years were unable to work and all had thoracic curves exceeding $100^{\circ}$. None of the patients between 20 and 65 years of age was engaged in hard work and $22 \%$ had a disability pension, all because of respiratory impairment. A tendency to increased shortness of breath was noted with increasing curves as well as age.

Dynamic and static spirometry was performed and airway closure was studied with the xenon-133 bolus technique. With increasing degrees of scoliosis there was a reduction in all lung volumes. Seventeen of $\mathbf{4 0}$ patients showed evidence of airway closure at lung volumes greater than functional residual capacity; 6 of these patients were under 40 years of age, and all had thoracic scoliosis exceeding $90^{\circ}$.
\end{abstract}

During the last decade surgical treatment of young patients with scoliosis has become more widely accepted (Harrington, 1963; Moe and Ramon, 1964 ; Cauchoix, Duriez, and Ghosez, 1966; DeWald, Lambert, and Ray, 1966), and interest in detailed cardiopulmonary studies of this disease has also increased. A number of reports have been published on the influence of scoliosis on pulmonary function, chiefly correlating spirometric values with the angulation of the curve (Bergofsky, Turino, and Fishman, 1959; Bühlmann and Gierhake, 1960 ; Cotrel, 1965 ; Dollery, Gillam, Hugh-Jones, and Zorab, 1965 ; Fishman, 1965 ; de Coster and Remacle, 1967). Long-term follow-up studies have suggested a significantly increased mortality in patients with untreated idiopathic scoliosis (Nachemson, 1968; Nilsonne and Lundgren, 1968). The working capacity of the survivors was also found to be greatly reduced and a relatively high percentage of these patients showed cardiopulmonary impairment (Nachemson, 1968), which seemed to become of special importance around the age of 40 years. It was also noticed that a majority of the deaths occurred around that age (Nachemson, 1968 ; Nilsonne and Lundgren, 1968).

The present study was undertaken in an attempt to correlate, in a representative group of patients with untreated idiopathic scoliosis, the influence on lung function of the degree of the curve and of age, using both static and dynamic spirometry and the xenon-133 $\left({ }^{133} \mathrm{Xe}\right)$ bolus method for studying airway closure (Dollfuss, Milic-Emili, and Bates, 1966-67).

\section{MATERIAL}

A clinical evaluation was made of 50 subjects (11 males and 39 females) between 11 and 78 years of age with an earlier untreated idiopathic scoliosis. The 23 patients who were 30 years or less had been admitted for treatment to the Department of Orthopaedics, Göteborg, during the time of the investigation. The 27 patients aged 31 to 78 years were randomly selected from the survivors of material previously presented on the long-term results of untreated scoliosis (Nachemson, 1968). In that series 56 patients were found to have an idiopathic or 'congenital' (i.e., detected before 1 year of age) curve, and this time nearly $50 \%$ of them were subjected to a more detailed clinical, radiological, and respiratory study. Of these 27 patients, 5 were 31 to 40 years old, 7 were 41 to 50,9 were 51 to 60,5 were 61 to 70 , and 1 was 78 years.

The curves were classified as thoracic if the apical vertebra was located in Th III-Th X and as thoracolumbar if the apex of the curve was located in Th XIL II (James, 1965). No pure lumbar curves were seen, but four patients had double primary curves with the vertex of the curve located in Th VIII + L I, Th VII + L II, Th III+Th X, and Th VII +L II, respectively. In the present analysis only the upper curve was con- 
sidered since it was regarded as the most important in the impairment of pulmonary function.

As this study aimed mainly at obtaining information on lung function in scoliotic patients as a function of curvature and age, the patients were divided into two age groups $(<40 ; \geqslant 40 \mathrm{yr})$ and into three groups of increasing curves $\left(<60^{\circ}, 60-99^{\circ}, \geqslant 100^{\circ}\right)$ (Table I).

Airway closure was studied in $\mathbf{4 0}$ patients (Table II). Seven of the patients in whom this was not performed had curves of less than $60^{\circ}$.

\section{T A B L E I}

PATIENTS STUDIED ACCORDING TO ANGULATION AND LOCALIZATION OF THE CURVATURE AND AGE

\begin{tabular}{|c|c|c|c|c|c|c|c|}
\hline \multirow[b]{2}{*}{ Age (yr) } & \multicolumn{2}{|c|}{$<60^{\circ}$} & \multicolumn{2}{|c|}{$60-99^{\circ}$} & \multicolumn{2}{|c|}{$\geqslant 100^{\circ}$} & \multirow{2}{*}{ Total } \\
\hline & $<40$ & $\geqslant 40$ & $<40$ & $\geqslant 40$ & $<40$ & $\geqslant 40$ & \\
\hline $\begin{array}{l}\text { Thoracic } \\
\text { Th II-Th X } \\
\text { Thoraco-lumbar } \\
\text { Th XI-L II }\end{array}$ & $\begin{array}{l}9 \\
0\end{array}$ & $\begin{array}{l}5 \\
7\end{array}$ & $\begin{array}{l}7 \\
0\end{array}$ & $\begin{array}{l}4 \\
2\end{array}$ & $\begin{array}{r}10 \\
1\end{array}$ & $\begin{array}{l}5 \\
0\end{array}$ & $\begin{array}{l}40 \\
10\end{array}$ \\
\hline
\end{tabular}

\section{T A B L E I I}

PATIENTS STUDIED WITH ${ }^{133}$ XE BOLUS TECHNIQUE FOR AIRWAY CLOSURE

\begin{tabular}{|c|c|c|c|c|c|c|c|}
\hline \multirow[b]{2}{*}{ Age (yr) } & \multicolumn{2}{|c|}{$<60^{\circ}$} & \multicolumn{2}{|c|}{$60-99^{\circ}$} & \multicolumn{2}{|c|}{$\geqslant 100^{\circ}$} & \multirow{2}{*}{ Total } \\
\hline & $<40$ & $\geqslant 40$ & $<40$ & $\geqslant 40$ & $<40$ & $\geqslant 40$ & \\
\hline $\begin{array}{l}\text { Thoracic } \\
\text { Thoraco- }\end{array}$ & 3 & 4 & 6 & 4 & 9 & 5 & 31 \\
\hline lumbar & 0 & 7 & 0 & 1 & 1 & 0 & 9 \\
\hline
\end{tabular}

\section{METHODS}

CLINICAL INVESTigation Determination of the apical vertebra and measurement of the angulation of the curve was made, according to Cobb (1948), from radiographs taken in the standing position. At the clinical examination the patients were asked in detail about their occupation and participation in physical activities as well as being given the questionnaire concerning pulmonary disturbances approved by the College of General Practitioners (1961).

PHYSIOLOGICAL INVESTIGATION Static spirometry, including the subdivisions of vital capacity (VC), was determined in the sitting position. The functional residual capacity (FRC) was measured with the helium dilution technique. Tidal volume was recorded during quiet breathing. Dynamic spirometry was performed on a modified Bernstein spirometer. For predicting normal values a corrected height was used, according to Bjure, Grimby, and Nachemson (1968). ${ }^{1}$ The normal

IIn that paper the regression equation for the relation between the loss of trunk height $(y)$ and the angulation of the curvature $(x)$ was given with an erroneous sign. The correct equation is $\log y=0.011 x-0.177(r=0.94)$ values were predicted according to the formulae given by Berglund, Birath, Bjure, Grimby, Kjellmer, Sandquist, and Söderholm (1963), and Grimby and Söderholm (1963), and for patients under 18 years of age according to the formula of Bjure (1963) for VC and according to Cook and Hamann (1961) for other lung volumes. Airway closure was studied in the sitting position with the ${ }^{133} \mathrm{Xe}$ bolus technique described by Dollfuss et al. (1966-67) and Holland, Milic-Emili, Macklem, and Bates (1968). At residual volume (RV) a $1-2 \mathrm{ml}$. bolus of ${ }^{133} \mathrm{Xe}$ was immediately injected into the mouth, whereafter the patient inspired slowly (over a period of about 10 seconds) to total lung capacity (TLC). The patient then expired very slowly (over a 10-20 second period) to $\mathrm{RV}$. The ${ }^{133} \mathrm{Xe}$ activity was continuously measured with a scintillation counter at the mouth connected to a ratemeter with a time constant of $0 \cdot 1$ second (Bake, Bjure, Grimby, Milic-Emili, and Nilsson, 1967) and recorded on the $y$-axis of an $x$-y recorder with the expired volume on the $\mathrm{x}$-axis.

The recordings of ${ }^{133} \mathrm{Xe}$ concentration as a function of expired volume have four phases (Dollfuss et al., 1966-67 ; Holland et al., 1968): (1) dead space gas; (2) mixed alveolar and dead space gas; (3) alveolar

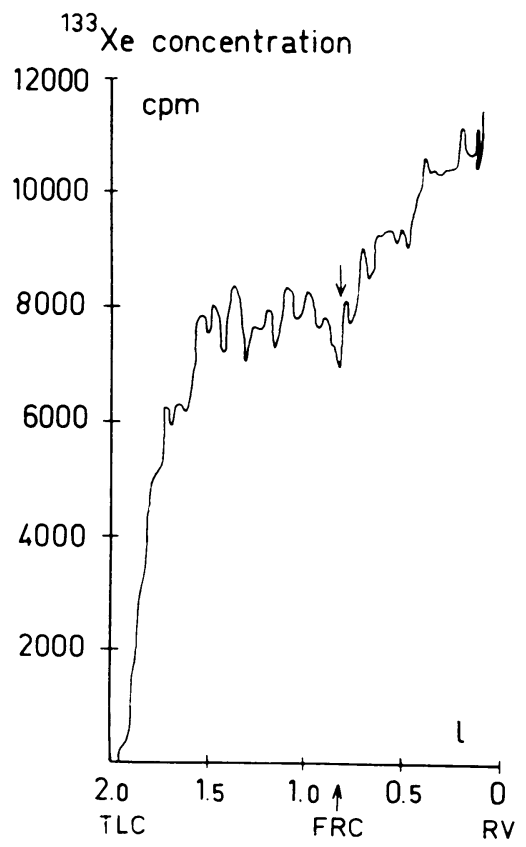

FIG. 1. Relation between ${ }^{133} \mathrm{Xe}$ concentration in expired air and expired volume following an inspiratory vital capacity with a bolus of ${ }^{133} \mathrm{Xe}$ inhaled at $R V$. The arrow indicates the volume at which airway closure starts to occur (phase 4). The patient is a 28-year-old woman with a high thoracic curve of $90^{\circ}$ and vital capacity of $52 \%$ of the predicted normal value. 
gas with a plateau of ${ }^{133} \mathrm{Xe}$ concentration; and (4) a phase with increasing ${ }^{133} \mathrm{Xe}$ concentration, indicating that there is airway closure.

The lung volume corresponding to the junction of phases 3 and 4 represents the volume at which the airways start to close and is called the closing volume. A typical recording from one patient is shown (Fig. 1). Usually two acceptable curves were recorded and the mean value is presented.

\section{RESULTS}

Clinical INVESTIGation As seen in Table III, there is a correlation between increasingly severe shortness of breath on the one hand and increasing curvature and age on the other. With regard

\section{T A B L E I I I}

DEGREE OF DYSPNOEA IN RELATION TO ANGULATION

\begin{tabular}{|c|c|c|c|c|c|c|c|}
\hline \multirow{2}{*}{\multicolumn{2}{|c|}{ Age (yr) }} & \multicolumn{2}{|c|}{$<60^{\circ}$} & \multicolumn{2}{|c|}{$60-99^{\circ}$} & \multicolumn{2}{|c|}{$\geqslant 100^{\circ}$} \\
\hline & & $<40$ & $\geqslant 40$ & $<40$ & $\geqslant 40$ & $<40$ & $\geqslant 40$ \\
\hline $\mathbf{V}$ & $\begin{array}{l}\text { Dyspnoea from } \\
\text { dressing or } \\
\text { similar } \\
\text { activities }\end{array}$ & & & & & 1 & 2 \\
\hline IV & $\begin{array}{l}\text { Need to stop } \\
\text { due to dys- } \\
\text { pnoea on } \\
\text { walking alone } \\
\text { on level } \\
\text { ground }\end{array}$ & & & & 2 & 2 & \\
\hline III & $\begin{array}{l}\text { Dyspnoea on } \\
\text { accompanied } \\
\text { walking at } \\
\text { normal speed } \\
\text { on level } \\
\text { ground }\end{array}$ & & & 2 & & 4 & 3 \\
\hline II & $\begin{array}{l}\text { Dyspnoea on } \\
\text { walking fast } \\
\text { or up a small } \\
\text { hill }\end{array}$ & 1 & 32 & 1 & 1 & 11 & \\
\hline I & $\begin{array}{l}\text { No com- } \\
\text { plaints }\end{array}$ & 8 & 25 & 4 & 11 & 2 & 1 \\
\hline Tota & $\begin{array}{l}\text { Thoracic } \\
\text { Thoraco-lumbar }\end{array}$ & 90 & 57 & $\begin{array}{ll}7 & 0\end{array}$ & 32 & $\begin{array}{ll}10 & \\
& 1\end{array}$ & $\begin{array}{ll}6 & \\
& 0\end{array}$ \\
\hline
\end{tabular}

T A B L E IV

WHEEZING IN RELATION TO ANGULATION OF THE CURVATURE AND AGE

\begin{tabular}{|c|c|c|c|c|c|c|}
\hline \multirow[b]{2}{*}{ Age (yr) } & \multicolumn{2}{|c|}{$<60^{\circ}$} & \multicolumn{2}{|c|}{$60-99^{\circ}$} & \multicolumn{2}{|c|}{$\geqslant 100^{\circ}$} \\
\hline & $<40$ & $\geqslant 40$ & $<40$ & $\geqslant 40$ & $<40$ & $\geqslant 40$ \\
\hline $\begin{array}{l}\text { More constant wheezing } \\
\text { apart from colds }\end{array}$ & & & 1 & & 1 & 2 \\
\hline $\begin{array}{l}\text { Wheezing apart from } \\
\text { colds }\end{array}$ & & 1 & & 2 & 1 & \\
\hline No complaints & 9 & 47 & 6 & 21 & $\begin{array}{ll}8 & 1 \\
\end{array}$ & 4 \\
\hline $\begin{array}{l}\text { Total: Thoracic } \\
\text { Thoraco-lumbar }\end{array}$ & 90 & 57 & ${ }^{7} 0$ & 41 & \begin{tabular}{ll|}
10 & \\
& 1
\end{tabular} & ${ }^{6} 0$ \\
\hline
\end{tabular}

to symptoms of wheezing no definite correlation is found with age or curvature (Table IV). It is also seen in these Tables that none of the patients with thoraco-lumbar curves suffers from any significant degree of dyspnoea or has any signs of bronchitis. Among those with symptoms of dyspnoea (groups III to $\mathrm{V}$ in Table III) over the age of 40 ( 7 patients), four have a disability pension because of scoliosis and one is a 78-yearold man. Two have sedentary jobs. It should be mentioned that of the six patients over 60 years of age, three have mild curves $\left(30\right.$ to $\left.40^{\circ}\right)$, while the remainder have curves of $65^{\circ}, 90^{\circ}$, and $110^{\circ}$ respectively, with the largest curvature in a 78 year-old man, who, in spite of a deformed spine, had worked until the age of 65 as a sea captain. At the present time he shows severe dyspnoea (grade V). His scoliosis, however, is of a short 'congenital' type with the apex at Th X.

Of those over the age of 20 , with curves exceeding $60^{\circ}$ ( 23 patients), 8 receive a disability pension due to scoliosis, 11 are engaged in light work and 4 in medium heavy work. No one is doing heavy manual work, nor is any of these patients actively engaged in sports. The 5 patients under 40 years

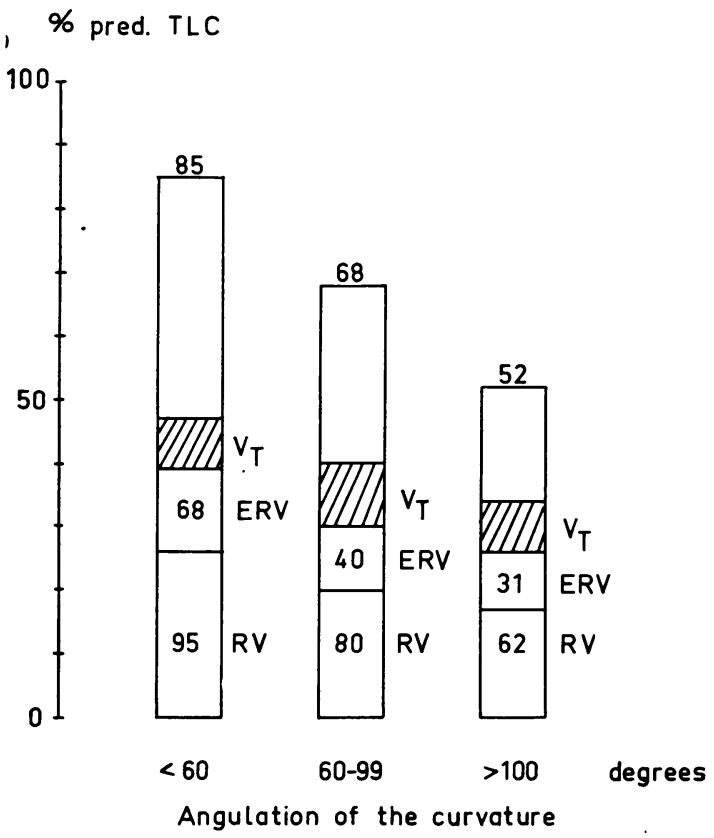

FIG. 2. Total lung capacity (TLC) and its subdivisions expressed in per cent predicted TLC for the three groups of patients with untreated idiopathic scoliosis. For ERV and $R V$ are also given the per cent of the predicted normal values. 
of age, who are unable to work, have mid-thoracic curves of $110^{\circ}$ or more.

No neurological symptoms of significance were noted. Back pain was reported as an occasional

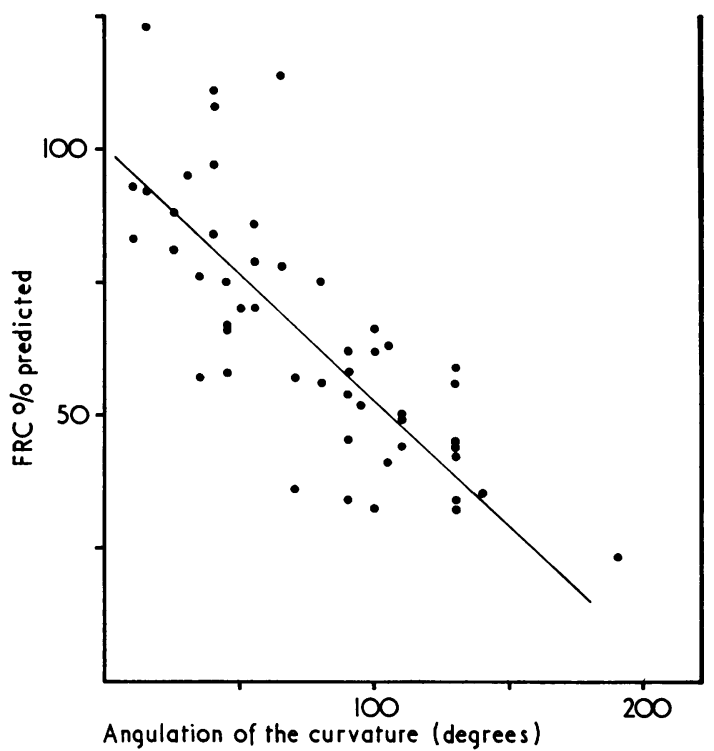

FIG. 3. Relation between FRC in per cent of predicted normal value $(y)$ and the angulation of the curvature $(x)$. Regression equation: $y=-0.45 x+99.0(r=0.78$, $R S D=14 \cdot 9$ ). symptom in 16 of the 27 patients over 30 years of age. In none, however, were these symptoms severe enough to constitute the main cause of the decreased working ability.

PhYSIOLOGICAl INVESTIGation Dynamic spirometry revealed no airway obstruction in any of the 50 patients studied.

With increasing curvature there is a fall in TLC; in patients with curves $<60^{\circ}$ it is $85 \%$ of predicted normal values, in patients with curves $>60^{\circ}-<100^{\circ} 68 \%$, and in patients with curves $>100^{\circ} 52 \%$ (Fig. 2). The regression equation for the relation between TLC in per cent of the predicted normal value (y) and angulation of the curvature $(x)$ is

$$
y=-0.42 x+100 \cdot 9(r=0.88, R S D=9 \cdot 6) \text {. }
$$

In the three groups $\mathrm{VC}$ in per cent predicted is 83 , 64 , and $46 \%$, respectively. The regression equation for the relation between VC in per cent of the predicted normal value $(y)$ and angulation of the curve $(x)$ is

$$
y=-0.43 x+98 \cdot 3(r=0.86, R S D=10 \cdot 5) \text {. }
$$

RV decreases less than VC and TLC, being 95, 80, and $62 \%$ predicted, respectively.

The respiratory mid-position shows a tendency to decrease with increasing degrees of scoliosis, as illustrated by the relation between FRC in per cent of the predicted normal value (y) and angula-

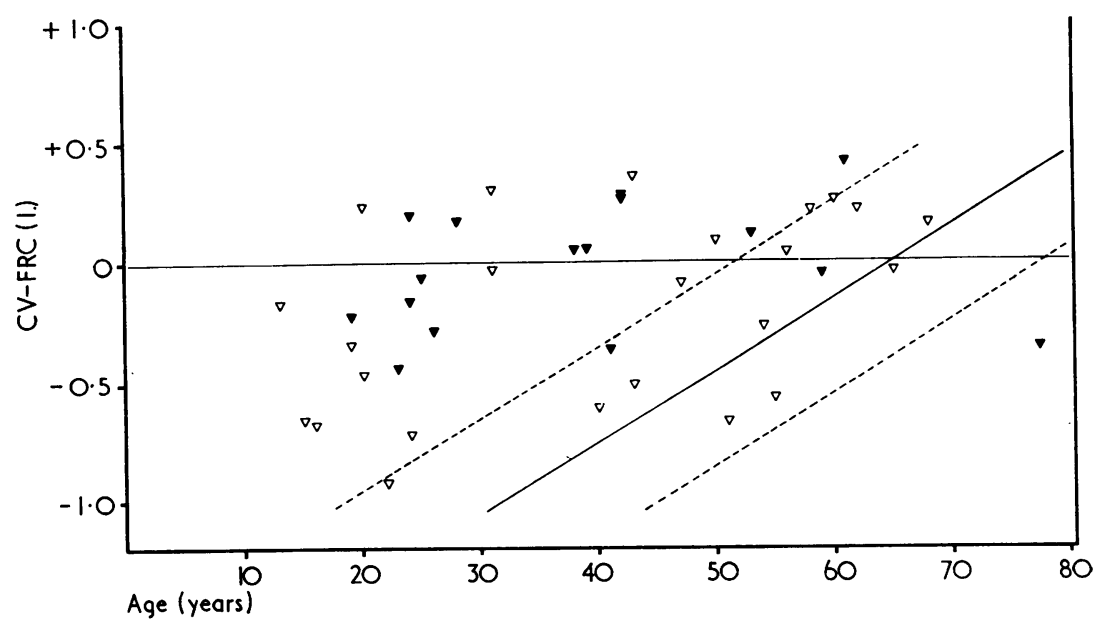

FIG. 4. Closing volume (CV) minus functional residual capacity $(F R C)$ in relation to age. Values above the zero line indicate that the airway closure occurs above FRC. Filled symbols indicate patients with a significant degree of dyspnoea (groups III to $V$ in Table III). The regression line (solid) is drawn according to the equation CV$F R C=0.03 \times$ age -1.95 derived by Leblanc et al. (1969) from a study of 84 healthy men and 6 women. The broken line indicates \pm one standard deviation. 
tion of the curve $(x)$,

$$
y=-0.45 x+99 \cdot 0(r=0 \cdot 78, \operatorname{RSD}=14.9)
$$

(Fig. 3). No significant correlation between lung volume and degree of dyspnoea is found.

In 17 of the 40 patients tested with the ${ }^{133} \mathrm{Xe}$ bolus technique the airway starts to close at a lung volume greater than FRC. This occurs in patients of all ages (Fig. 4). Three of these 17 patients, all over 50 years of age, have thoraco-lumbar scoliosis. No significant correlation between airway closure above FRC and a significant degree of dyspnoea (groups III to $\mathrm{V}$ in Table III) can be found.

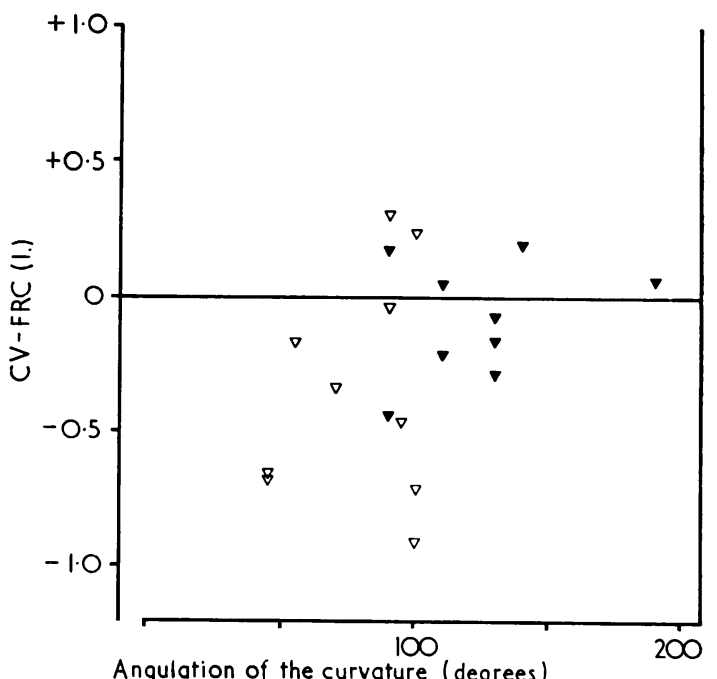

FIG. 5. Closing volume (CV) minus functional residual capacity $(F R C)$ in relation to angulation of the curvature in patients under 40 years of age. Filled symbols indicate patients with a significant degree of dyspnoea (groups III to $V$ in Table III).

Airway closure above FRC occurs in 6 of 19 patients under the age of 40 (Fig. 5). These 6 patients all have thoracic curves of $90^{\circ}$ or more. The closing volume ( $\mathrm{CV}$ in 1.) is found to be correlated with age, body height $(\mathrm{cm}$.), and angulation of the curvature (degrees) according to the multiple regression equation:

$$
\begin{gathered}
\mathrm{CV}=0.0131 \times \text { age }+0.0165 \times \text { height }-0.004 \times \\
\text { angulation }-1.38(\mathrm{r}=0.78, \mathrm{RSD}=0.28) .
\end{gathered}
$$

The regression equation between closing volume in per cent of the predicted normal TLC (y) and angulation of the curvature $(x)$ is :

$$
y=-0 \cdot 16 x+43 \cdot 0(r=0 \cdot 67, \operatorname{RSD}=8 \cdot 0) \text {. }
$$

DISCUSSION

Clinical examination corroborates the previous finding (Nachemson, 1968) that a lateral curvature of the spine significantly reduces the working capacity of the patient. None of the patients over the age of 20 years with curves of $60^{\circ}$ or more is engaged in hard work and no less than 8 of the total 38 patients over the age of 20 receive disability pensions, which were granted to them on account of scoliosis. All seven patients below the age of 60 who are unable to work have curves exceeding $100^{\circ}$.

No less than $22 \%$ of the patients between 20 and 65 years of age are unable to work. Compared with the incidence of disability in the general population, this is a highly significant increase (Nachemson, 1968).. It should be noted that the patients over 30 years of age are randomly selected from the survivors of a previously studied group of patients (Nachemson, 1968) with untreated scoliosis, in whom a significantly increased morbidity as well as an increased mortality from pulmonary impairment was found. Since that study was based mainly on questionnaires and only a few clinical and radiological examinations, it was impossible to correlate the disability with the degree of scoliosis. From the present investigation, however, it is obvious that patients with an idiopathic scoliosis already above $100^{\circ}$ at a relatively young age run a great risk of becoming disabled. The only exception in this study is the 78-year-old man who had worked at sea until the aged of 65 , but he was found to have a short, low thoracic curve probably of congenital origin.

With regard to dyspnoea the clinical follow-up also shows a clear tendency to increasingly severe shortness of breath with increasing curves as well as age. No patient has symptoms of severe bronchitis and only four have symptoms of mild bronchitis. As already demonstrated in several previous reports (Chapman, Dill, and Graybiel, 1939; Bergofsky et al., 1959; Bühlmann and Gierhake, 1960 ; Mankin, Graham, and Schack, 1964 ; Cotrel, 1965; Fishman, 1965; de Coster and Remacle, 1967; Bjure et al., 1968), there is a fall in total lung capacity and vital capacity as the angulation of the curve increases. The patients in the present study also show a reduction of functional residual capacity so that with an increasing degree of scoliosis there is a decrease in the respiratory midposition. This means that some of them may breathe normally at a lung volume at which the airways start to close (Holland et al., 1968). Leblanc, Ruff, and Milic-Emili (1969) have 
recently shown that in the sitting position the airways start to close above FRC in normal subjects over the age of 65 . In all of their subjects under the age of 40 it occurred at a lung volume below FRC, whereas 6 of our 19 subjects below that age had airway closure above FRC (Figs 4 and 5). There are, in this study, even some patients, young as well as old, who have some airways closed throughout most of the resting breathing cycle. One of the possible reasons for the increased frequency of respiratory disturbances in scoliotic patients may be the airway closure leading to uneven distribution of the relation between ventilation and perfusion. In the scoliotic patients with airway closure below FRC this usually occurs at a lung volume higher than expected from normal subjects. In the scoliotic patient airway closure above FRC is probably still more common in the supine position than in the sitting position, as in normal supine persons this has been shown to occur by the age of 44 (Leblanc et al., 1969). Our findings may indicate that airway closure, which occurs also in young patients with severe scoliosis, is one of the aetiological factors in the development of respiratory impairment in these patients.

This study was supported by a grant from the Swedish National Association against Heart and Chest Diseases.

\section{REFERENCES}

Bake, B., Bjure, J., Grimby, G., Milic-Emili, J., and Nilsson, N. J. (1967). Regional distribution of inspired gas in supine man. Scand. J. resp. Dis., 48, 189.

Berglund, E., Birath, G., Bjure, J., Grimby, G., Kjellmer, I., Sandquist, L., and Söderholm, B. (1963). Spirometric studies quist, L., and Söderholm, B. (1963). Spirometric studies in normal subjects. I. Forced expirograms in sub 70 years of age. Acta med. scand., 173, 185 .

Bergofsky, E. H., Turino, G. M., and Fishman, A. P. (1959). Cardiorespiratory failure in kyphoscoliosis. Medicine (Baltimore), 38, 263.

Bjure, J. (1963). Spirometric studies in normal subjects. IV. Ventilatory capacities in healthy children 7-17 years of age. Acta Paediat. (Uppsala), 52, 232.

Grimby, G., and Nachemson. A. (1968). Correction of body height in predicting spirometric values in scoliotic patients. Scand. J. clin. Lab. Invest., 21, 190.
Bühlmann, A., and Gierhake, W. (1960). Die Lungenfunktion bei $\overline{\widehat{C}}$ der jugendlichen Kyphoskoliose. Schweiz. med. Wschr..90, 1153

Cauchoix, J., Duriez, J., and Ghosez, J.-P. (1966). L'arthrodèse vertébrale pour scoliose par avivement et apposition de greffons cortico-spongieux autogènes. Rev. Chir. Orthop., 52, 241.

Chapman, E. M., Dill, D. B. and Graybiel, A. (1939). The decrease in functional capacity of the lungs and heart resulting from $\mathbb{D}$ deformities of the chest: Pulmonocardiac failure. Medicine (Baltimore), 18, 167

Cobb, J. R. (1948). Outline for the study of scoliosis. Amer. Acad. Orthop. Surg. Lect., 5, 261.

College of General Practitioners (1961). Chronic bronchitis in Great Britain. Brit. med. J., 2, 973.

Cook, C. D., and Hamann, J. F. (1961). Relation of lung volumes to height in healthy persons between the ages of 5 and 38 years. J. Pediat., 59, 710.

de Coster, A., and Remacle, P. (1967). La fonction pulmonaire des cyphoscoliotiques. Acta orthop. belg., 33, 551.

Cotrel, Y. (1965). Conservative management of scoliosis. In Proceedings of a Symposium on Scoliosis, edited by P. A. Zorab, p. 18. National Fund for Research into Poliomyelitis and other $\frac{A}{\mathrm{c}}$ Crippling Diseases, Vincent House, London.

DeWald, R. L., Lambert, C. N., and Ray, D. R. (1966). Internal 음 instrumentation in the treatment of scoliosis. Surg. Clin. N. Amer., 46, 55.

Dollery, C. T., Gillam, P. M. S., Hugh-Jones, P., and Zorab, P. A. C (1965). Regional lung function in kyphoscoliosis. Thorax,

ollfuss, R. E., Milic-Emili, J., and Bates, D. V. (1966-7). Regional $\overrightarrow{0}$ ventilation of the lung studied with boluses of ${ }^{133}$ Xenon. Resp. Physiol., 2, 234.

Fishman, A. P. (1965). Pulmonary aspects of scoliosis. In Proceeding of a Symposium on Scoliosis, edited by P. A. Zorab, p. 52 . National Fund for Research into Poliomyelitis and other National Fund for Research into Polio
Crippling Diseases, Vincent House, London.

Grimby, G., and Söderholm, B. (1963). Spirometric studies in normal subjects. III. Static lung volumes and maximum voluntary ventilation in adults with a note on physical fitness. Acta med. scand., 173, 199.

Harrington, P. R. (1963). The management of scoliosis by spine instrumentation: an evaluation of more than 200 cases. Sth. med. J. (Bgham, Ala.), 56, 1367.

Holland, J., Milic-Emili, J., Macklem, P. T., and Bates, D. V. (1968). Regional distribution of pulmonary ventilation and perfusion in elderly subjects. J. clin. Invest., 47, 81 .

James, J. I. P. (1965). Classification and prognosis. In Proceedings of a Symposium on Scoliosis, edited by P. A. Zorab, p. 11. National Fund for Research into Poliomyelitis and other Crippling Diseases, Vincent House, London.

Leblanc, P., Ruff, F., and Milic-Emili, J. (1969). Effects of age and body position on airways closure in man. In manuscript.

Mankin, H. J., Graham, J. J., and Schack, J. (1964). Cardiopulmonary function in mild and moderate idiopathic scoliosis. J. Bone Jt Surg., 46A, 53. Moe, J. H., and Ramon, B. G. (1964). Treatment of scoliosis. J.

Nachemson, A. (1968). A long-term follow-up study of non-treated $ᄋ$ scoliosis. Acta orthop. scand., 39, 466.

Nilsonne, U., and Lundgren, K. D. (1968). Long-term prognosis I in idiopathic scoliosis. Acta orthop. scand., 39, 456. 